\title{
Retraction Note to: Prediction water absorption resistance of lightweight geopolymers by artificial neural networks
}

\author{
Ali Nazari ${ }^{1}$
}

Published online: 4 July 2020

(c) Springer-Verlag London Ltd., part of Springer Nature 2020

Retraction to: Neural Comput \& Applic (2019) 31 (Suppl 2):S759-S766 https://doi.org/10.1007/s00521-012-1136-6

The Editor-in-Chief has retracted this article [1] because it significantly overlaps with a number of articles including those that were under consideration at the same time [2] and previously published articles [3-6]. Additionally, the article shows evidence of peer review manipulation. The author has not responded to any correspondence regarding this retraction.

\section{References}

1. Nazari A (2019) Prediction water absorption resistance of lightweight geopolymers by artificial neural networks. Neural Comput Appl 31:759-766. https://doi.org/10.1007/s00521-0121136-6
2. Nazari A (2012) Artificial neural networks for prediction of percentage of water absorption of geopolymers produced by waste ashes. Bull Mater Sci 35:1019-1029. https://doi.org/10.1007/ s12034-012-0380-9

3. Nazari A (2013) Artificial neural networks application to predict the compressive damage of lightweight geopolymer. Neural Comput Appl 23:507-518. https://doi.org/10.1007/s00521-0120945-y

4. Nazari A (2013) Artificial neural networks for prediction compressive strength of geopolymers with seeded waste ashes. Neural Comput Appl 23:391-402. https://doi.org/10.1007/s00521-0120931-4

5. Nazari A (2013) Utilizing ANFIS for prediction water absorption of lightweight geopolymers produced from waste materials. Neural Comput Appl 23:417-427. https://doi.org/10.1007/s00521-0120934-1

6. Nazari A (2012) Fuzzy logic for prediction water absorption of lightweight geopolymers produced from waste materials. Ceram Int 38(6):4729-4736. https://doi.org/10.1016/j.ceramint.2012.02.058

Publisher's Note Springer Nature remains neutral with regard to jurisdictional claims in published maps and institutional affiliations.
The original article can be found online at https:// doi.org/10.1007/s00521-012-1136-6.

\section{Ali Nazari}

alinazari84@aut.ac.ir

1 Department of Materials Science and Engineering, Islamic Azad University, Saveh Branch, Saveh, Iran 